\title{
The profile and clinical outcomes of patients with renal involvement due to $\lg A$ vasculitis: is azathioprine a good option for treatment?
}

\author{
Vânia Schinzel ${ }^{1}$, Jade Dib Fernandez ${ }^{1}$, Gleice Clemente ${ }^{1}$, Melissa Mariti Fraga ${ }^{1}$, Maria Cristina Andrade², \\ Claudio Arnaldo Len ${ }^{1}$ and Maria Teresa Terreri ${ }^{i^{*}}$
}

\begin{abstract}
Background: The Henoch-Schönlein Purpura (HSP) orlgA vasculitis is the most common vasculitis of childhood and may occur with renal involvement, with hematuria and / or proteinuria, and may cause severe and non-reversible sequelae.

Objectives: To establish the profile of patients with renal involvement due to IgA vasculitisand to describe our experience with the use of azathioprine to treat patients with nephritis.

Methods: Clinical data were retrospectively collected from medical records of patients with IgA vasculitiswho attended the pediatric rheumatology unit between 1995 and 2017. Patients were separated into two groups based on whether or notthey weretreated with non-glucocorticoid immunosuppressants.
\end{abstract}

Results: From the178 patients with IgA vasculitis,nephritis was found in67 patients (37.6\%), 13 of whom receivedtreatment with non-glucocorticoid immunosuppressants. Ten patients responded well to azathioprine and 1 patient to cyclosporine. Forty patients received oral glucocorticoids, whilst 16received intravenous glucocorticoids.

Conclusion: Azathioprine may be beneficial in the treatment of IgA vasculitis with renal involvement.

Keywords: Henoch-Schönlein Purpura, IgA vasculitis, Nephritis, Vasculitis, Childhood, Azathioprine

\section{Background}

Henoch-Schönlein Purpura (HSP) or IgA vasculitisis the most common type of vasculitis found in children and it is characterized by small vessel involvement. The clinical manifestations of IgA vasculitis include the sudden appearance of palpable non-thrombocytopenic purpura, mainly on the inferior limbs, which may be accompanied by abdominal pain, arthritis and nephritis [1-3].

The disease course is, in general, benign and selflimited. However, gastrointestinal complications, such as intestinal bleeding or intussusception, may occur during the acute phase of the disease. In addition, renal involvement may develop during the acute or chronic phase,

\footnotetext{
* Correspondence: teterreri@terra.com.br

${ }^{1}$ Pediatric Rheumatology division, Pediatric Department, Universidade Federal de São Paulo, Rua Borges Lagoa, 802, São Paulo, SP 04038-001, Brazil Full list of author information is available at the end of the article
}

presenting as proteinuria and/or hematuria, which occasionally leads to systemic arterial hypertension and renal failure $[1,4]$.

Renal injury is the primary cause of morbidity in IgA vasculitisand occurs in $90 \%$ of cases during the first eight weeks after the purpuraonset, and in about $97 \%$ of cases, in the first six months [5-7]. In cases of persistent hematuria and proteinuria, a renal biopsy is indicated to confirmdiagnosis, by revealingmesangial deposits of immunoglobulin A (IgA) and, in some cases, C3 deposit [8-11].

Latin American studies on IgA vasculitis are scarce. A Brazilian study with 296 patients showed that about one half of them presented renal involvement in the first three months of follow-up and persistent purpura and gastrointestinal bleeding were associated with nephritis [12]. Another publication from the same group described in a multivariate analysis severe abdominal pain 
as the only predictor factor for nephritis [13]. Furthermore another study showed that patients with disease recurrence presented renal involvement more frequently than those with monocyclic disease [14].

Recent studies failed to demonstrate benefits fromthe early use of glucocorticoids to avoid renal injury [8, 15-17], although some studies in adults with IgA nephropathy have shown improvement in the glomerular filtration rate (GFR) and a reduction in proteinuria [8]. In cases of major renal impairment, immunosuppressive agents have been used; however, more trials are needed to evaluate the efficacy of this treatment option $[16,17]$. The guidelinesfrom the Kidney Disease Improving Global Outcomes (KDIGO) recommend the use of intravenous glucocorticoids associated with cyclophosphamide to treat crescentic glomerulonephritis [18]. Some medications,such as the angiotensin converting enzyme inhibitors (ACE-I), are indicated to control persistent proteinuria [8].

The protocol used by our tertiary pediatric rheumatology centre follows the guidelines recommended by the KDIGO, and includescyclophosphamideused in severe cases when the renal biopsy shows crescents in over 50\% ofthe glomeruli, or azathioprine in other cases of persistent renal impairment.

The goal of this study was to establish the profile of patients with renal impairmentdue to IgA vasculitis and to describe our experience using azathioprine in nephritis.

\section{Methods}

This was a retrospective longitudinal study, with a convenience sample, which evaluatedall patients with IgA vasculitisattended in a tertiary center of pediatric rheumatology, between 1995 and 2017. Data from patients that met the criteria used byOzenet al. [1] and who had complete medical records available, were included in the analysis. Data describing patient demographics, clinical and laboratory tests, treatment and outcomes were collected from the medical records.

We defined recurrencewhen a new episode of purpura occurs after three months without any clinical signs or symptoms of the disease; chronicity was defined as the persistence of cutaneous alterations for at least three months [14]. We considered renal impairment whenhematuria was greater than 10,000 cells $/ \mathrm{mL}$, or in presence of hematic cylinderon urine analysis or in presence of proteinuria (non-nephrotic if $\geq 5 \mathrm{mg} / \mathrm{kg} /$ day but $<50 \mathrm{mg} /$ $\mathrm{kg} /$ day, or nephrotic if $\geq 50 \mathrm{mg} / \mathrm{kg} /$ day). Renal impairment was classified as initial or in the course of the disease, when the alterations were found within the first month, or diagnosed after one month of the onset of the purpuric symptoms, respectively. A diagnosis of systemic arterialhypertension was confirmed after three measurements above the 95th percentile, in accordance with the guidelines from the Brazilian Pediatric Society [19].
Chronic renal injury was defined as the presence ofstructural or functional alterations for at least three months, or a glomerular filtration rate $<60 \mathrm{ml} / \mathrm{min} /$ $1.73 \mathrm{~m}^{2}$ for longer than three months [20].

Findings in renal biopsy were classified in 6 subtypes according to literature taking into account the presence and severity of the crescentic disease [21].

Scrotal, pulmonary and neuropsychiatric involvement were defined according to the literature [22].

Patients with renal impairment were separated into two groups: one by those who did not use non-glucocorticoid immunosuppressants (Group 1) and the other by those who used non-glucocorticoid immunosuppressants (Group 2).

The results are presented using percentages and the analysis was made using the chi-squared or Fisher's tests, by SPSS24 statistical software. A significance level of 5\% $(p<0.05)$ was set. This study was approved by the ethics and research committee of our institution.

\section{Results}

Between 1995 and 2017, 178 patients with IgA vasculitisattended our clinic. Among them, 67 (37.6\%) had renal impairment and were selected for the analysis: 42 (62.6\%) were female, in a 1.68:1 ratio. In patients with renal impairment, the mean age at onset of IgA vasculitissymptoms was 7.3 years $( \pm 3.1)$ and the mean disease duration was 5.5 years $( \pm 3.2)$. All patients with nephritis had cutaneous manifestations, six (8.9\%)of whom had skin necrosis or ulcerations. Intestinal manifestations of IgA vasculitis were seen in 47 patients (70.1\%), and arthritis was present in 41 patients (61.1\%).

Renal involvement occurred during the initial phase in 53 cases $(79.1 \%)$. Of the 67 cases with renal involvementpresent in any phase of the disease, 59 patients (88\%) had hematuria (22 of them presented isolated hematuria), which was macroscopic in 14 patients $(20 \%)$; in 43 patients $(64.1 \%)$ proteinuria was identified, being nephrotic in 10 of these cases (14.9\%). Urine analysis remained altered for a mean of 13.3 months. Renal function impairmentwas observed in one patient (1.4\%). Systemic arterial hypertension was present in ten patients (14.9\%). Group 2 had a higher frequency of nephrotic proteinuria, nephritic syndrome and systemic arterial hypertension than Group 1; on the other hand, the group 1 presented a higher frequency of isolated hematuria. There was no statistically significant difference in renal functionimpairment and in the presence of microscopic and macroscopic hematuria between groups ( $p=0.209, p=0.34$ and $p=0.27$, respectively). A renal biopsy was performed in 20 patients (29.8\%) and was indicated in those with severe disease, or persistent hematuria and/or proteinuria. Table 1 shows the characteristics of the 67 patients with renal involvement. 
Table 1 Demographic data and clinical manifestations of the 67 patients with nephritis due to Henoch-Schönlein Purpura

\begin{tabular}{|c|c|c|c|c|}
\hline Demographic and clinical data & $\begin{array}{l}\text { Total number } \\
N=67(\%)\end{array}$ & $\begin{array}{l}\text { Patients off immunosuppressants } \\
N=54(\%)\end{array}$ & $\begin{array}{l}\text { Patients on immunosuppressants } \\
N=13(\%)\end{array}$ & $p$-value \\
\hline Female & $42(62.6)$ & $36(66)$ & $6(46.1)$ & $0.680^{*}$ \\
\hline Age at onset (mean age in years, min. - max.) & $7(2-15)$ & $6.5(2-15)$ & $8.0(4-11)$ & $0.453^{* * *}$ \\
\hline Time of follow up (median in years, min-max.) & $4.0(1-12)$ & $2(1-12)$ & $4(1-9)$ & $<0.001^{* * *}$ \\
\hline Cutaneous necrosis or ulcerations & $6(8.9)$ & $5(9.2)$ & $1(7.6)$ & $0.190^{* *}$ \\
\hline Intestinal Impairment & $47(70.1)$ & $37(68.5)$ & $10(76.9)$ & $1.0^{* *}$ \\
\hline Intestinal bleeding & $15(22.3)$ & $13(24)$ & $2(15.3)$ & $0.719^{* *}$ \\
\hline Arthritis & $41(61.1)$ & $32(59.2)$ & $9(69.2)$ & $0.604^{*}$ \\
\hline Initial renal impairment & $53(79.1)$ & $40(74)$ & $13(100)$ & \\
\hline Microscopic hematuria & $45(67.1)$ & $41(75.9)$ & $4(30.7)$ & $0.349^{* *}$ \\
\hline Macroscopic hematuria & $14(20.8)$ & $7(12.9)$ & $7(5 ., 8)$ & $0.277^{* *}$ \\
\hline Isolated hematuria & $22(32.8)$ & $22(40)$ & 0 & $0.003^{* *}$ \\
\hline Isolated proteinuria & $6(8.9)$ & $5(9.2)$ & $1(7.6)$ & $0.790^{* *}$ \\
\hline Non-nephrotic proteinuria & $33(49.2)$ & $29(5.7)$ & $4(30.7)$ & $0.206^{*}$ \\
\hline Nephrotic proteinuria & $10(14.9)$ & $1(1.8)$ & $9(69.2)$ & $0.000^{* *}$ \\
\hline Nephritic syndrome & $6(8.9)$ & $1(1.8)$ & $5(38)$ & $0.001^{* *}$ \\
\hline Kidney biopsy & $20(29.8)$ & $10(18.5)$ & $10(76.9)$ & $0,0002^{* *}$ \\
\hline Reduction of renal function & $1(1.5)$ & 0 & $1(7.6)$ & $0.209^{* *}$ \\
\hline Systemic Arterial Hypertension & $12(17.9)$ & $5(9.2)$ & $7(53.8)$ & $0.001^{* *}$ \\
\hline Scrotal involvement & 0 & 0 & 0 & 0 \\
\hline Pulmonary involvement & 0 & 0 & 0 & 0 \\
\hline Neuropsychiatric involvement & 0 & 0 & 0 & 0 \\
\hline Pulse therapy with IVglucocorticoid & $16(23.8)$ & $7(12.9)$ & $9(69.2)$ & $0.000^{* *}$ \\
\hline Oral glucocorticoid & $40(59.7)$ & $27(39.7)$ & $13(100)$ & $0.045^{*}$ \\
\hline
\end{tabular}

SD standard deviation, $I V$ intravenous; ${ }^{*}$ chi-squared test; ${ }^{* *}$ Fisher's test; ${ }^{* * *}$ Mann-Whitney's test

With regards to treatment, 40 patients $(59.7 \%)$ received oral glucocorticoids ( 1 to $2 \mathrm{mg} / \mathrm{kg} /$ day) and 16 patients $(23.8 \%$ received a monthly course of intravenous glucocorticoids $(30 \mathrm{mg} / \mathrm{kg} /$ day) for three consecutive days, for one to seven months. Thirteen patients (19.4\%) were treated with non-glucocorticoid immunosuppressants, such as azathioprine, cyclophosphamide or mycophenolate sodium.

In relation to the 13 patients who were onnonglucocorticoid immunosuppressants (Table 2), two were lost to medical follow up. All others received an ACE-I as treatment for proteinuria. The maximal proteinuria was related to the first presentation (Table 2). Ten patients complained of abdominal pain andone of them had hematemesis. However, there was no statistically significant difference between the two groups when general intestinal manifestations or the occurrence of intestinal bleeding were analyzed ( $p=1.0$ and $p=0.719$, respectively).

Ten patients had total or partial recovery after being treated with azathioprine. Their follow up can be seen in Fig. 1. Only one patient was treated with cyclophosphamide (seven cycles), chosen because of the presence of
$100 \%$ crescents inhis glomeruli in the renal biopsy. This resulted in a reduction in proteinuria from $376 \mathrm{mg} / \mathrm{kg} /$ day to $40 \mathrm{mg} / \mathrm{kg} /$ day. As there was no further improvement in proteinuria azathioprine was initiated; however, this patient did not show significant improvement after nine months of treatment. As such, the treatment was changed to mycophenolate, also without an adequate response. The fourth medication chosen as a treatment option was cyclosporine, achieving a full resolution of the renal disease after four months of treatment.

\section{Discussion}

In our sample of 178 patients with IgA vasculitis, we found renal involvement in approximately one third of the analyzed population, which is similar to what is reported in the literature $[5-7,23]$. As expected, the majority of patients had a favorable outcome without requiring intravenous glucocorticoid or non-glucocorticoid immunosuppressants, although more than half of the cases used oral glucocorticoids to treat severe cutaneous or intestinal manifestations. A study comparing pediatric and adult population showed 
Table 2 Characteristics of the thirteen patients with renal impairment due to Henoch-Schönlein Purpura in use of azathioprine

\begin{tabular}{|c|c|c|c|c|c|c|}
\hline $\bar{P}$ & G & Age & $\begin{array}{l}\text { GFR } \\
\text { T0 / T1 } \\
\left(\mathrm{ml} / \mathrm{min} / 1.73 \mathrm{~m}^{2}\right)\end{array}$ & $\begin{array}{l}\text { Pt max } \\
\text { T0 } \\
\text { (mg/kg/day) }\end{array}$ & Hematuria & Biopsy \\
\hline 1 & $\mathrm{~F}$ & 6 & $60 / 201.6$ & 88 & micro & $\begin{array}{l}\text { Proliferative glomerulonephritis with segmental crescents. Presence of IgA, } \\
\text { C3, kappa and lambda deposits. }\end{array}$ \\
\hline 2 & $\mathrm{~F}$ & 5 & $99 / 121.2$ & 17.4 & - & Not performed. \\
\hline 3 & M & 11 & $135.6 / 162.8$ & 79 & macro & $\begin{array}{l}\text { Segmental sclerosis in } 4 / 9 \text { glomeruli,mesangial deposits of IgA, C3, kappa } \\
\text { and lambda. }\end{array}$ \\
\hline 4 & M & 8 & 132 / NP & 148 & - & Not performed - lost to medical follow up. \\
\hline 5 & M & 10 & 113.6 / NP & 20 & - & Not performed - lost to medical follow up. \\
\hline 6 & $\mathrm{~F}$ & 5 & $126.5 / 127.6$ & 144 & micro & Slight increase of mesangial cells, with IgA mesangial deposits. \\
\hline 7 & M & 4 & $43.21 / 100.8$ & 24 & macro & IgA and IgM glomerular deposits and mesangial C3 deposits. \\
\hline 8 & M & 6 & $182.7 / 147.9$ & 396 & macro & 100\%crescents andlgA and polyclonal C3 deposits. \\
\hline 9 & M & 10 & $104.5 / 104.5$ & 30 & micro & Segmental glomerular sclerosis Glomerular mesangial deposits of IgA. \\
\hline 10 & $\mathrm{~F}$ & 6 & $293.33 / 220$ & 150 & macro & Glomerular mesangial deposits of IgA. \\
\hline 11 & M & 10 & $112.3 / 94.1$ & 20 & micro & Discrete proliferative mesangial glomerulonephritis, with IgA mesangial deposits. \\
\hline 12 & $\mathrm{~F}$ & 11 & $117 / 117.8$ & 261 & micro & $\begin{array}{l}\text { Focal segmental proliferative necrotizing glomerulonephritis, with 30\% crescents, } \\
\text { with deposits of } \lg \mathrm{A} \text {, IgM and C3. }\end{array}$ \\
\hline 13 & $\mathrm{~F}$ & 9 & $126.5 / 108.4$ & 95 & micro & $\begin{array}{l}\text { Diffuse proliferative mesangial glomerulonephritis, focal necrotizing glomerulitis } \\
\text { with fibrocellular crescents and } \lg \mathrm{A} \text { and } \mathrm{C} 3 \text { deposits. }\end{array}$ \\
\hline
\end{tabular}

$P$ patient, $G$ gender, Age - in years; GFR: Glomerular Filtration Rate; T0 - initial; T1 - after one year; Pt: proteinuria; M - male; F - female; macro- macroscopic; micro - microscopic

better prognosis in children [24] and favorable outcome has been improved throughout the years [25].

Due to a lack of data regarding the long term follow up of patients with HSP nephritis, the KDIGO guidelines recommend the use of ACE-I or Angiotensin II Receptor Blockers (ARB) to treat patients with proteinuria $>0.5 \mathrm{~g} /$ day, including nephrotic proteinuria, as a first line treatment option for three to six months, before a decision to add glucocorticoids is made [18]. These recommendations, which are based on data from adult patients with IgA nephropathy, do not seem appropriate for children with HSP, since we know that delaying the introduction of glucocorticoids may increase the risk of chronic renal disease.

A double-blind, placebo-controlled study showed a faster resolution of nephritis in the group treated with oral glucocorticoids, when compared with the placebo group [18]. Therefore, there is no consistent data to determine the correct moment to initiate treatment with glucocorticoids. Similarly, there is no consensus regarding the ideal duration of treatment with ACE-I or ARB prior to the introduction of glucocorticoids.

Concerning the 67 patients who had renal involvement, the use of non-glucocorticoid immunosuppressants was

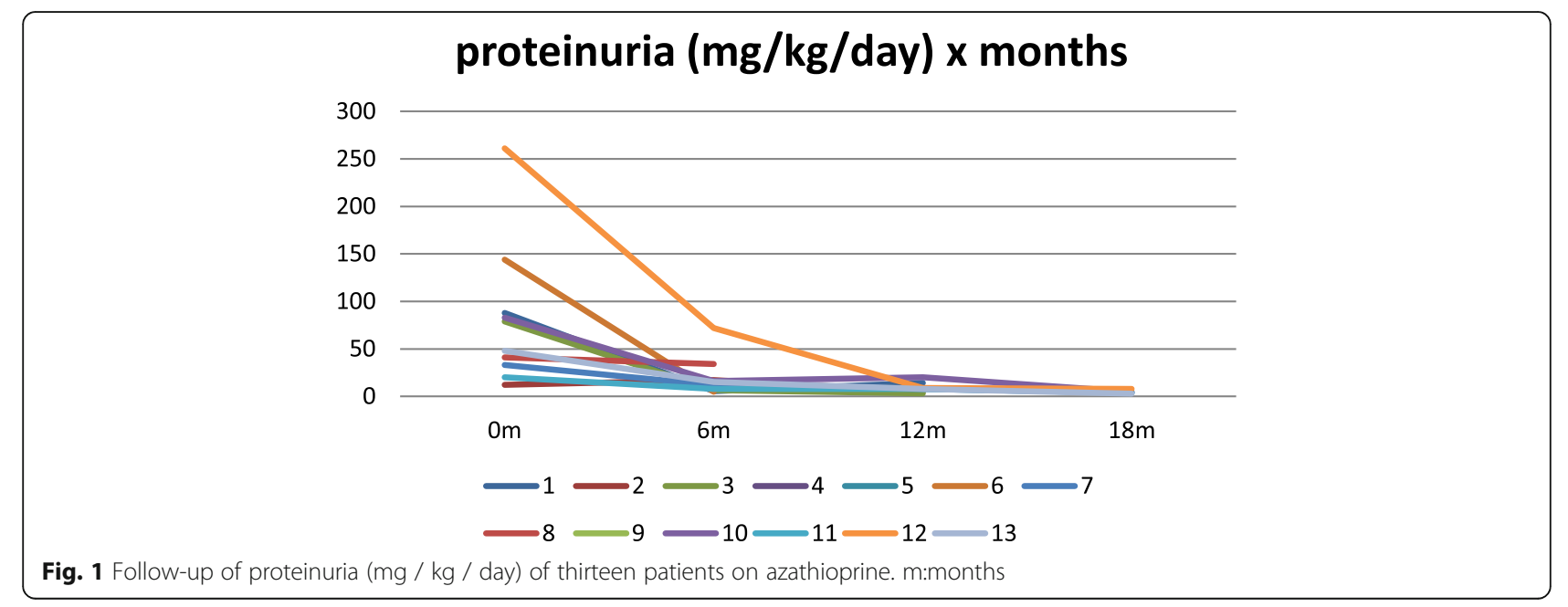


administered to 13 patients (19.4\%) who presented with severe renal manifestations, such as nephrotic proteinuria, or persistent hematuria and/or proteinuria on urine analysis. Although 10 of these 13 patients had had intestinal manifestations (such as abdominal pain), only one (7.6\%) presented with intestinal bleeding or hematemesis. These results are in contrast with what has been reported in a few studies that correlated the severity of abdominal pain to renal involvement [26].

Regarding the use of non-glucocorticoid immunosuppressants, azathioprine may be beneficial in the treatment of renal involvement, which was demonstrated by the significant improvement in laboratory tests after six months of treatment, with a total or partial reduction of abnormalities on urine analysis in most cases. However is important to mention that proteinuria decrease can not be attributed solely to azathioprine use since this group also received glucocorticoids and ACE-I. These results are similar to what has been reported previously in the literature [27-29]. The combination of AZA, GC and ACE-I appears to be effective in reducing proteinuria in the first 6 months of treatment and this was particularly important since the group receiving the triple therapy was more severe in the baseline (higher frequency of nephrotic syndrome and nephritic syndrome). Even though there is no evidence supporting the use of azathioprine in cases of nephritis due to IgA vasculitis, some studies have described a good clinical response and a reduction in IgA mesangial deposits, in post-treatment renal biopsy [27-30]. A trial comparing treatment with azathioprine to therapy with mycophenolate for a year, in 18 children with IgA vasculitis, showed proteinuria resolution in all $10 \mathrm{pa}-$ tients treated with mycophenolate and in 6 of the 8 children treated with azathioprine. All the patients received oral glucocorticoids for six months but did not use ACE-I [31].

Due to the scarcity of data available on treatment for the Latin American population getting more information on effective treatment can minimize the risk of chronic renal disease. This is the strong point of our study.

The limitations of our study are the retrospective nature, the small number of patients who used immunosuppressants, baseline demographic differences of renal impairment between groups and short follow-up time that do not allow comparison of treatment response who used or not immunosuppressants. Concerning oral glucocorticoid use, some patients had already received the medication before they attended our clinic for the first time. Hence, we are not able to guarantee that the initial prescription of glucocorticoids was correctly indicated. An initial biopsy or even a second biopsy, in cases where results of the initial biopsy were inconclusive, was not possible to perform in all patients.

\section{Conclusion}

Nephritis due to IgA vasculitis generally has a benign course, resolving itself spontaneously or after low doses of glucocorticoids; however, in cases in which nonglucocorticoid immunosuppressants are needed, azathioprine may lead to a favorable outcome. Nevertheless, multicenter prospective and randomized studies are necessary to better evaluate the efficacy of azathioprine in cases of nephritis due to IgA vasculitis.

\section{Acknowledgements \\ We would like to thank Wellington D. R. Rodrigues for his collaboration with the statistical analysis. \\ Funding \\ This study did not receive funding or financial support. \\ Availability of data and materials \\ The data sets used and/or analysed during the current study are available from the corresponding author on reasonable request.}

Authors' contributions

VS: bibliographic review, data collection, introduction, methods, results, discussion; JDF: translate; GC: bibliographic review, introduction, statistic, methods, results, discussion; MMF: bibliographic review. CAL: bibliographic review. MCA: bibliographic review. MTT: introduction, methods, results, discussion. All authors read and approved the final manuscript.

Ethics approval and consent to participate

This study was approved by the Ethics and Research Committee of UNIFESP - Federal University of São Paulo. Number: 36577614.5.0000.5505.

Consent for publication

Not applicable

\section{Competing interests}

The authors declare that they have no competing interests

\section{Publisher's Note}

Springer Nature remains neutral with regard to jurisdictional claims in published maps and institutional affiliations.

\section{Author details}

${ }^{1}$ Pediatric Rheumatology division, Pediatric Department, Universidade Federal de São Paulo, Rua Borges Lagoa, 802, São Paulo, SP 04038-001, Brazil.

${ }^{2}$ Pediatric Nephrology division, Pediatric Department, Universidade Federal de São Paulo, São Paulo, Brazil.

Received: 16 August 2018 Accepted: 1 May 2019

Published online: 22 May 2019

\section{References}

1. Ozen S, Pistorio A, lusan SM, Bakkaloglu A, Herlin T, Brik R, et al. For the Paediatric rheumatology international trials organisation (PRINTO). EULAR/ PRINTO/PRES criteria for Henoch-Schönlein purpura, childhood polyarteritis nodosa, childhood Wegener granulomatosis and childhood Takayasu arteritis: Ankara 2008. Part II: final classification criteria. Ann Rheum Dis. 2010; 69:798-806.

2. Jennette JC, Falk RJ, Bacon PA, Basu N, Cid MC, Ferrario F, et al. Revised international Chapel Hill consensus conference nomenclature of Vasculitis. Arthritis Rheum 2013. 2012;65:1-11. 
3. Youying M, Lei $Y$, Hua H, Fu H, Shen H, Wang J, et al. Henoch-Schönlein purpura in 535 Chinese children: clinical features and risk factors for renal involvement. J Int Med Res. 2014;42:1043-9.

4. Feng $D$, Huang $W Y$, Hao NXL, Wang $P, W u Y$, et al. A single-center analysis of Henoch-Schonlein purpura nephritis with nephrotic proteinuria in children. Pediatr Rheumatol Online J. 2017:15:15.

5. Aulsbury FT. Clinical update: Henoch-Schonlein purpura. Lancet. 2007;369: 976-8.

6. Narchi H. Risk of long-term renal impairment and duration of follow up recommended for Henoch-Schonlein purpura with normal or minimal urinary findings: a systematic review. Arch Dis Child. 2005;90:916-20.

7. Saulsbury FT. Henoch-Schonlein purpura in children. Report of 100 patients and review of the literature. Medicine (Baltimore). 1999;78:395-409.

8. Trnka P. Henoch-Schönlein purpura in children. J Paediatrics Child Health. 2013:49:995-1003.

9. Davin JC, Weening JJ. Diagnosis of Henoch-Schönlein purpura: renal or skin biopsy? Pediatr Nephrol. 2003;18:1201-3.

10. Algoet C, Proesmans W. Renal biopsy 2-9 years after Henoch-Schönlein purpura. Pediatr Nephrol. 2003;18:471-3.

11. Novak J, Julian BA, Tomana M. MesteckyJ.IgA glycosylation and IgA immune complexes in the pathogenesis of IgA nephropathy. Semin Nephrol. 2008; 28:78-87.

12. Buscatti IM, Casella BB, Aikawa NE, Watanabe A, Farhat SCL, Campos LM, et al. Henoch-Schönlein purpura nephritis: initial risk factors and outcomes in a Latin American tertiary center. Clin Rheumatol. 2018;37(5):1319-24.

13. de Almeida JL, Campos LM, Paim LB, Leone C, Koch VH, Silva CA. Renal involvement in Henoch-Schönlein purpura: a multivariate analysis of initial prognostic factors. J Pediatr. 2007:83(3):259-66.

14. Alfredo CS, Nunes NA, Len CA, Barbosa CM, Terreri MT, Hilário MO. HenochSchönlein purpura: recurrence and chronicity. J Pediatr. 2007;83(2):177-80.

15. Dudley J, Smith G, Llewelyn-Edwards A, Bayliss K, Pike K, Tizard J. Randomised, double-blind, placebo-controlled trial to determine whether steroids reduce the incidence and severity of nephropathy in HenochSchönlein Purpura (HSP). Arch Dis Child. 2013;98:756-63.

16. Chartapisak W, Opastirakul S, Hodson EM, Willis NS, Craig JC. Interventions for preventing and treating kidney disease in Henoch-Schönlein Purpura (HSP) (review). Evid-Based Child Health. 2010;5:637-700.

17. Zaffanello M, Fanos V. Treatment-based literature of Henoch-Schönlein purpura nephritis in childhood. Pediatr Nephrol. 2009;24:1901-11.

18. KDIGO 2012 Clinical Practice Guideline for the Evaluation and Management of Chronic Kidney Disease. Kidneylnt (Suppl). 2013;3:1-150.

19. Koch VH, Furusawa EA. Diretrizes para medida da pressão arterial, MAPA e MRPA.2015. SociedadeBrasileira de Pediatria.

20. National Kidney Foundation. KDOQI clinical practice guidelines for chronic kidney disease: evaluation, classification, and stratification. Am J Kidney Dis. 2002;39:S1-266.

21. Counahan R, Winterborn MH, White RHR, Heaton JM, Meadow SR, Bluett $\mathrm{NH}$, et al. Prognosis of Henoch-Schönleinnephritis in children. BMJ. 1977;2: $11-4$.

22. Brogan P, Bagga A. Textbook of pediatric rheumatology, vol. 33. 7th ed; 2016. p. 452-61 e2.

23. Chen $O$, Zhu XB, Ren P, Wang YB, Sun RP, Wei DE. Henoch Schönlein Purpura in children: clinical analysis of 120 cases. Afr Health Sci. 2013;13(1):94-9.

24. Batu ED, Sari A, Erden A, Sönmez HE, Armag B, Kalyoncu U, et al. Comparing immunoglobulin A vasculitis (Henoch- Schoenlein and purpura) in children and adults: a single-Centre study from Turkey. Scand J Rheumatol. 2018; 47(6):481-6

25. Yamane K, Kawasaki Y, Maeda R, Ohara S, Suyama K, Hosoya M. The incidence and severity of IgA vasculitis with nephritis over a 10-year period in our hospital. Fukushima J Med Sci. 2017;63(3):135-40.

26. Shin Jl, Park JM, Shin YH, Hwang DH, Kim JH, Lee JS. Predictive factors for nephritis, relapse, and significant proteinuria in childhood HenochSchönlein purpura. Scand J Rheumatol. 2006;35(1):56-60.

27. Bergstein J, Leiser J, Andreoli SP. Response of crescentic Henoch-Schönlein purpura nephritis to corticosteroid and azathioprine therapy. Clin Nephrol. 1998:49:9-14.

28. Foster BJ, Bernard C, Drummond KN, Sharma AK. Effective therapy for severe Henoch-Schönlein purpura nephritis with prednisone and azathioprine: a clinical and histopathologic study. J Pediatr. 2000;136:370-5.

29. Singh S, Devidayal KL, Joshi K, Minz RW, Datta U. Severe Henoch-Schönlein nephritis: resolution with azathioprine and steroids. Rheumatollnt. 2002;22:133-7.
30. Naija O, Bouzaraa J, Goucha-Louzir R, Gargah T. Henoch Schönlein nephritis in children: clinical features and outcome: about 34 cases. TunisMed. 2013; 91(12):700-4.

31. Fuentes $Y$, Valverde $S$, Valesquez-Jones $L$, et al. Comparison of azathioprine vs mofetil mycophenolate for Henoch-Schönlein nephritis treatment (abstract). Pediatr Nephrol. 2010;25:1802

\section{Ready to submit your research? Choose BMC and benefit from:}

- fast, convenient online submission

- thorough peer review by experienced researchers in your field

- rapid publication on acceptance

- support for research data, including large and complex data types

- gold Open Access which fosters wider collaboration and increased citations

- maximum visibility for your research: over $100 \mathrm{M}$ website views per year

At $\mathrm{BMC}$, research is always in progress.

Learn more biomedcentral.com/submissions 